\title{
Alveolar Adenoma
}

National Cancer Institute

\section{Source}

National Cancer Institute. Alveolar Adenoma. NCI Thesaurus. Code C4140.

A benign, well circumscribed lung neoplasm morphologically characterized by the presence of cystic spaces resembling alveoli, lined by a simple cuboidal epithelium. The cystic spaces are surrounded by a spindle cell stroma which may show myxoid changes. It is a solitary, usually peripheral lung lesion. Patients are usually asymptomatic and its discovery is an incidental finding during chest X-ray examination. Surgical excision is curative. 